\title{
REDRAWING THE BOUNDARIES: R. DVORKIN'S INTERPRETATIVISM IN THE LIGHT OF TRADITIONAL TYPOLOGIES OF LEGAL THEORIZING ${ }^{1}$
}

\author{
Sergey N. Kasatkin \\ Samara Law Institute of the FSIN of Russia, Samara, Russian Federation; \\ Samara State University of Economics, Samara, Russian Federation
}

\begin{abstract}
Introduction: the paper is devoted to the interpretative concept of the outstanding American jurist Ronald Dworkin, formulated in his "Law's Empire" (1986) and a number of other works. The subject of the paper is the characteristic of R. Dvorkin's methodological approach. As its basis the author uses the interpretation of a "methodological model" of the thinker, proposed by the Mexican researcher Imer Flores, which is valuable for the effort to relate a (polemical and only partly explicit) approach of the American jurist with the classical criteria system of the typology of legal doctrines. Accordingly, the paper aims to identify (using the general scientific and specific scientific methods) R. Dworkin's interpretativism in the context of the basic divisions of legal theories in modern Western (Anglo-American) jurisprudence, as well as to establish the impact of interpretativism on existing legaltheoretical typologies. As a result, the paper, first, outlines the key ideas of R. Dworkin's doctrine, and secondly, examines I. Flores's interpretation of the content and meaning of the interpretive methodology, thirdly, assesses the validity of such an interpretation with the justification of the status of interpretativism in the system of classical types of legal theorizing and its methodological implications. As a general conclusion, the paper argues for the status of R. Dworkin's doctrine as a private and normative jurisprudence of the "internal point of view". I. Flores's thesis about the unification of traditional types of legal theories in interpretativism and transcending the dichotomy between positivism and natural law is disputed. Interpretativism challenges the established system of criteria for differentiating legal theories, rejecting a number of relevant methodological perspectives, primarily a general descriptive and morally neutral theory of law. By defending a necessary connection between law and morality, interpretativism, in fact, legitimizes the claims of natural-law concepts as to a proper explanation of "law as it is", transferring their long-standing dispute with positivism to a new - methodological - level.
\end{abstract}

Key words: R. Dvorkin, legal interpretativism, hermeneutical theory of law, legal interpretation, types of legal theories, methodology of jurisprudence, legal positivism.

Citation. Kasatkin S.N. Redrawing the Boundaries: R. Dvorkin's Interpretativism in the Light of Traditional Typologies of Legal Theorizing. Legal Concept = Pravovaya paradigma, 2020, vol. 19, no. 4, pp. 80-88. (in Russian). DOI: https://doi.org/10.15688/lc.jvolsu.2020.4.11

УДК $340.11 ; 340.12$

Дата поступления статьи: 20.11.2020

ББК $67.0 ; 67.1$

Дата принятия статьи: 08.12.2020

\section{ПЕРЕКРАИВАЯ ГРАНИЦЫ: ИНТЕРПРЕТАТИВИЗМ Р. ДВОРКИНА В СВЕТЕ ТРАДИЦИОННЫХ ТИПОЛОГИЙ ПРАВОВОГО ТЕОРЕТИЗИРОВАНИЯ 1}

\section{Сергей Николаевич Касаткин}

Самарский юридический институт ФСИН России, г. Самара, Российская Федерация; Самарский государственный экономический университет, г. Самара, Российская Федерация

Введение: статья посвящена интерпретативной концепции выдающегося американского правоведа Рональда Дворкина, сформулированной им в «Империи права» (1986) и ряде других работ. Предметом статьи выступает характеристика методологического подхода Р. Дворкина. В качестве ее основы используется трактовка «методологической модели» мыслителя, предложенная мексиканским исследователем Имером Флоресом, ценная стремлением соотнести (дискуссионный и лишь отчасти эксплицированный) подход 
американского правоведа с системой классических критериев типологии правовых учений. Соответственно, цель статьи состоит в идентификации (с использованием общенаучных и частнонаучных методов) интерпретативизма Р. Дворкина в контексте базовых делений правовых теорий в современной западной (англо-американской) юриспруденции, а также в установлении следствий интерпретативизма для существующих теоретико-правовых типологий. Как результат, в работе, во-первых, очерчиваются ключевые идеи доктрины Р. Дворкина; во-вторых, исследуется трактовка содержания и значения интерпретативной методологии, данная И. Флоресом; в-третьих, оценивается состоятельность такой трактовки с обоснованием статуса интерпретативизма в системе классических типов правового теоретизирования и его методологических импликаций. В качестве общих выводов в статье аргументируется статус доктрины Р. Дворкина как частной и нормативной юриспруденции «внутренней точки зрения». Оспаривается тезис И. Флореса об объединении в интерпретативизме традиционных типов правовых теорий и преодолении им дихотомии позитивизма и естественного права. Интерпретативизм бросает вызов сложившейся системе критериев дифференциации правовых теорий, отвергая ряд связанных с ней методологических перспектив, прежде всего общую описательную и моральнонейтральную теорию права. Отстаивая необходимую связь права и морали, интерпретативизм, по сути, легитимирует притязания концепций естественно-правового толка на надлежащее объяснение «права как оно есть», переводя их давний спор с позитивизмом на новый - методологический - уровень.

Ключевые слова: Р. Дворкин, юридический интерпретативизм, герменевтическая теория права, юридическое толкование, типы правовых теорий, методология юриспруденции, юридический позитивизм.

Цитирование. Касаткин С. Н. Перекраивая границы: интерпретативизм Р. Дворкина в свете традиционных типологий правового теоретизирования // Legal Concept = Правовая парадигма. $-2020 .-$ T. 19, № 4. C. 80-88. - DOI: https://doi.org/10.15688/lc.jvolsu.2020.4.11

\section{Введение}

В отечественной литературе воззрения известного американского правоведа Рональда Дворкина, как правило, характеризуются с опорой на его «ранние» труды, прежде всего - книгу «О правах всерьез» (1977) [12]. Тем самым оставляются в стороне более поздние разработки автора, связанные с проектом юридического интерпретативизма и, по сути, выступающие одним из элементов «полемического ядра» современной англо-американской философии права и теоретической юриспруденции. Не являясь простым переформулированием своих работ 1960-1970-х гг., интерпретативные идеи Р. Дворкина (выраженные им в «Империи права» (1986) [11] и др.) образуют весьма оригинальную и провокационную модель правового теоретизирования - модель, альтернативную классическим доктринам права и традиционной правоведческой методологии и оказавшую существенное влияние на характер постановки и решения вопросов в современной западной теоретической юриспруденции. В этом плане учет идей Р. Дворкина видится значимым для правовой теории, создаваемой в текущем интеллектуальном контексте и озабоченной состоятельностью и востребованностью своих суждений.
В свете сказанного настоящая статья адресована прежде всего интерпретативной концепции Р. Дворкина и имеет общей целью экспликацию реализуемого им методологического подхода, который не получил системного изложения в «Империи права» и остается дискуссионным в зарубежной мысли. В качестве предметной основы работы используется трактовка «методологической модели» Р. Дворкина, предложенная известным мексиканским правоведом Имером Флоресом [14], ценная стремлением автора соотнести интерпретативизм с системой классических критериев типологии правовых учений. Соответственно, статья будет структурно включать, во-первых, очерк основных идей интерпретативизма Р. Дворкина, во-вторых, квалификацию И. Флоресом интерпретативной методологии Р. Дворкина и ее следствий для (англоамериканской) правовой мысли, в-третьих оценку обоснованности такой квалификации.

\section{Интерпретативизм Р. Дворкина: основные позиции}

Интерпретативная доктрина Рональда Дворкина, как она представлена в его фундаментальном труде «Империя права», включает целый ряд идей положительного и критического плана разной степени общности. Его наи- 
более важные позиции, соотносящие интерпретативизм с классическими концепциями права, можно изложить следующим образом.

Прежде всего Р. Дворкин ассоциирует право не с предзаданными историческими («простыми») фактами - официальными решениями и стандартами, а с системой практик обоснования правовых суждений. По мысли автора, юридическая практика носит прежде всего аргументативный (немеханический, нормативный, институциональный) характер, когда истинность или ложность правовых суждений, как и любых правил в системе, задается самой этой практикой, ее общим смыслом [11, p. 13]. В свою очередь, смысл юридической практики (в отличие от высказываний отдельных ее участников) можно постичь лишь через «конструктивное толкование», связанное с целями / решениями не автора, а интерпретатора и предполагающее «наложение» цели на объект с тем, чтобы представить его наилучшим примером соответствующей формы или жанра [11, p. 52].

Как следствие, настаивает Р. Дворкин, любые правовые суждения не являются чисто описательными или оценочными в отношении права (его истории), но носят комплексный - интерпретативный - характер [7, p. 147]. Отсюда, с одной стороны, судья, разрешающий дело, должен как установить общий смысл прежних решений, так и найти наилучший вариант их применения [7, ch. 5; 9, ch. 7]. С другой стороны, теоретик права, чтобы постичь смысл юридической практики, должен принять в ней участие, вовлекаясь в ее конструктивное истолкование и представляя право в наилучшем свете. Суждения теоретика и практика по природе едины, а теория права выступает общей интерпретативной основой любого юридического решения / вывода [11, p. 90].

На этой основе Р. Дворкин продвигает свою идею «права как целостности». Таковая предполагает, во-первых, обусловленность прав и обязанностей не только прошлыми юридическими решениями, но и лежащими в их основе принципами личной и политической морали [11, p. 96]; во-вторых, сочетание двух принципов «политической целостности»: законодательного принципа, призывающего законодателя к созданию морально непротиворе- чивой совокупности норм, и судебного принципа, предписывающего рассматривать право таким непротиворечивым образом [11, p. 176]; в-третьих, неприятие трактовок правовых суждений как ретроспективных отчетов «конвенционализма» (позитивизма) либо проспективных инструментальных программ «прагматизма» (реализма, экономического анализа права и т. п.), но их понимание как интерпретативных утверждений, которые включают оба таких элемента и толкуют юридическую практику как «разворачивающееся политическое повествование»: «право как целостность» отвергает бесполезный древний вопрос - находят ли судьи право или изобретают его, «мы понимаем правовое рассуждение... лишь постигая смысл, в котором судьи делают и то, и другое, и одновременно не делают ни того, ни другого» [11, p. 225].

\section{«Методологическая модель»} интерпретативизма: взгляд И. Флореса

Как отмечалось, в трудах Р. Дворкина фиксируются лишь некоторые черты его методологического подхода, что обусловливает ценность системной экспликации последнего для лучшего понимания интерпретативизма и его вклада в юриспруденцию. В связи с этим представляется интересным опыт решения данной задачи известным мексиканским правоведом, профессором национального автономного университета Мехико Имером Флоpecom.

Подходя к анализу «методологической модели» интерпретативизма, И. Флорес обращается к традиционным типологиям правовых теорий, принятым в западной (англо-американской) юриспруденции [2, гл. $1, \S 1 ; 3$, p. 1071; 4 , $\S 21-29 ; 6$, ch. $1-2 ; 15$, p. 239]. В числе исходных ученый называет, во-первых, деление правовых теорий на общие и частные (если первые адресованы тому, что присуще всем правовым системам или культурам, то вторые специфике конкретных систем или культур); во-вторых, деление теорий на описательные / объяснительные и нормативные / оправдательные (если первые отвечают на вопросы о том, что есть право, вопросы о фактах, то вторые - на вопросы о том, чем должно быть право, вопросы о ценностях). На этой основе 
автор выстраивает систему координат (см. таблицу), в рамках которой возможно определение правовых учений по двум названным параметрам: 1 - общие описательные, 2 общие нормативные, 3 - частные описательные и 4 - частные нормативные. Кроме того, здесь допускается создание более сложных теоретических комплексов (например, включающих переход от прояснения общих черт правовых систем или особенностей конкретной культуры (1 и 3 ) к их критике (2 и 4) [4, § 21-29]) и даже объединение всех методологических перспектив (1-4) [14, р. 167-170].

Сосредоточиваясь на отношениях теорий 1-го и 2-го типа, И. Флорес отмечает, с одной стороны, традиционное принятие нормативной / оправдательной позиции классическим юснатурализмом (полагающим, что нормативное исчерпывает содержание и природу права или что право сводимо к прескриптивному: «несправедливый закон законом не является»), с другой стороны - чисто описательное кредо позитивизма Джона Остина, Ганса Кельзена, Герберта Харта (нацеленного на объяснение «права, как оно есть» в противовес оправданию «права, каким оно должно быть») [14, p. 168-170]. Помимо этого, И. Флорес выделяет по вопросу и ряд более детальных позиций [14, p. 170-172]:

- признание независимости теорий 1-го и 2-го типа, а также строгая приверженность первому из них с допущением о моральном, а не правовом характере нормативного / оправдывающего измерения, а также возможности морально нейтрального или «косвенно оценочного» статуса теории права (жесткий / исключающий позитивизм) [6;18];

- допущение контингентных отношений теорий 1-го и 2-го типа при подчинении второго типа первому на основе того, что именно право включает отсылки к морали, а значит и его теория сводима к чисто понятийному анализу без нормативных или оправдательных целей (мягкий / включающий позитивизм) [5; 16];
- признание возможности и даже необходимости соединения 1-го и 2-го типа правовых теорий (нормативный позитивизм) [19; 20];

- соединение теорий 1-го и 2-го типа по максиме «несправедливый закон - закон действительный, но извращенный» («слабая» теория естественного права) [13].

Идентифицируя в этом контексте «методологическую модель» Рональда Дворкина, И. Флорес определяет его подход как: а) конструктивный, б) интерпретативный (аргументативный), в) оценочный и г) интегративный.

А. Конструктивность. По мысли ученого, начиная с рецензии на «Теорию справедливости» Джона Ролза (1973) [12, ch. 6] Р. Дворкин придерживается «конструктивной модели» философствования. Если «естественная модель» презюмирует описание открываемой людьми объективной моральной реальности, воссоздающее базовые принципы путем соединения в верном порядке конкретных суждений (как палеонтолог воссоздает животное по найденным костям), то «конструктивная модель» рассматривает интуиции справедливости как предполагаемые особенности формулируемой общей теории (подобно скульптору, вырезающему животное, наиболее подходящее к случайному набору костей). Такая модель презюмирует не объективные принципы справедливости, а скорее, ответственность людей (или должностных лиц) за сведение конкретных суждений, лежащих в основе их действий, в единую согласованную программу [12, p. 160; 14, p. 173-174].

Б. Интерпретативность. Согласно И. Флоресу, начиная с полемики со Стенли Фишем Р. Дворкин оценивает свой подход как конструктивный и отчасти творческий, при этом интерпретативный, а не изобретательный. Полагая право «интерпретативным понятием», постижимым лишь через «конструктивное толкование» практики, Р. Дворкин, с одной стороны, оспаривает «семантические теории» (прежде всего позитивизм), трактующие право как «критериальное понятие» или

\section{Система правовых теорий}

\begin{tabular}{|c|c|c|}
\hline & Описательные/объяснительные & Нормативные / оправдательные \\
\hline Общие & 1 & 2 \\
\hline Частные & 3 & 4 \\
\hline
\end{tabular}




\section{ТЕОРИЯ И ПРАКТИКА ГОСУДАРСТВЕННО-ПРАВОВОГО РАЗВИТИЯ}

«понятие естественного вида» с необходимым и достаточными признаками [9, p. 158-163; 10, p. 10-12; 11, p. 31-96]. С другой стороны, он, во-первых, определяет конструктивное толкование как «наложение цели на объект или практику с тем, чтобы представить их наилучшим примером формы или жанра, к которому, как считается, они относятся» - а это требует нахождения «равновесия» юридической практики и ее наилучшего оправдания, что, по И. Флоресу, означает «аргументативный» характер подхода Р. Дворкина [14, p. 175]. Вовторых, он выделяет три стадии конструктивного толкования: доинтерпретативную стадию, где устанавливаются правила и стандарты, которые обеспечивают предварительное содержание практики, интерпретативную стадию, на которой толкователь определяется с общим обоснованием выявленных ранее главных элементов практики, и постинтерпретативную, или реформирующую, стадию, на которой он правит свое понимание «действительных» требований практики так, чтобы оно лучше служило обоснованию, принятому на интерпретативной стадии $[11$, p. 66]. В-третьих, правовед настаивает на том, что природа подобного рассуждения скорее интерпретативна, чем изобретательна: обоснованию не нужно соответствовать каждому аспекту / особенности существующей практики - соответствие должно быть «достаточным, чтобы толкователь мог видеть, что он толкует практику, а не изобретает новую» $[11$, p. $66 ; 14$, p. 174-176].

В. Оченочность. По И. Флоресу: хотя, на первый взгляд, Р. Дворкин, формулируя идею права как толкования (1982) [7, ch. 5], принижает значение оценки и описания в пользу интерпретации, в итоге становится ясно, что он придерживается морального прочтения практики, требующего отсылок к ценности и даже объективных ценностных суждений. Р. Дворкин, с одной стороны, утверждает: правовые суждения не просто описательны в отношении истории права или оценочны в каком-то оторванном от нее смысле - они «толкуют историю права, сочетая элементы описания и оценки, но отличаясь от обоих из них» [7, p. 147]. С другой стороны, на примере феномена «учтивости» он раскрывает двухэлементность «интерпретативной установки». Первый элемент - это допущение, что прак- тика учтивости «не просто существует, но имеет ценность, служит определенному интересу, цели, реализует определенный принцип, короче, что она имеет определенный смысл, которые можно констатировать независимо от простого описания правил, составляющих эту практику» [11, p. 47]. Второй - это последующее допущение, что требования учтивости не являются необходимо или исключительно тем, чем, как считалось, они были всегда, но «чувствительны к ее смыслу, так что строгие правила должны пониматься, применяться, расширяться, изменяться или ограничиваться этим смыслом». По мере утверждения интерпретативной установки институт учтивости перестает быть механическим («слепым почитанием рунического порядка»): люди начинают стремиться «придать данному институту значение - увидеть его в наилучшем свете - а затем перестроить его в свете этого значения» [11, p. 47; 14, p. 176-177].

Г. Интегративность. Согласно И. Флоресу, если в «Империи права» Р. Дворкин строит концепцию «права как целостности» на идеях непротиворечивости и соответствия [11, ch. $7 ; 14$, p. 177-178], то далее он выходит на более фундаментальный уровень, критикуя общую идею обособленности ценностей - «архимедову» юриспруденцию и эпистемологию: он заявляет интегративную концепцию ценностей (тезис их единства), по которой каждая из них находит место в более общей, интерпретативной и взаимозависимой сети убеждений $[9$, p. 1, 14-19, 100; 10, p. 158-168]. Таким образом, право в итоге мыслится Р. Дворкиным уже как «политическое понятие» или «раздел политической морали», что смещает акценты с вопроса о взаимодействии права и морали как отдельных систем к вопросу о том, как выделять понятие права, чтобы показать его в качестве особой части понятия морали [9, p. 402-405; 14, p. 177-181].

В итоге, как резюмирует И. Флорес, Р. Дворкин формулирует оригинальную и влиятельную концепцию права с самобытной методологией. Эта концепция размывает границы не только между созданием и применением права, законотворчеством и судом, теорией и практикой, но и между классическими типами правовых доктрин, интегрируя различные (общие и частные, описательные и норматив- 
ные) методологические возможности в более сложную теоретико-правовую и общефилософскую рамку. Таким образом, она оспаривает не только теорию, но и саму методологию позитивизма как общего описательного и морально-нейтрального учения о праве, а также преодолевает давнюю дихотомию позитивизма и естественного права [14, p. 159-162, 172].

\section{Интерпретативизм как правовая теория: идентификация и следствия}

Анализ Имера Флореса фиксирует значимые особенности методологии Рональда Дворкина, а также связанную с ней проблематизацию классических делений правового теоретизирования. Однако, во-первых, выделяемые ученым черты интерпретативизма даются «списком», без анализа их взаимоотношений и указания их содержательной основы, порождающей размывание и объединение традиционных методологических позиций. Вовторых, выделенные черты не соизмеряются с классическими типами правовых доктрин (не говоря о молчании И. Флореса по значимому делению перспектив «участника» и «наблюдателя»), не позволяя четко вписать интерпретативизм в сложившуюся систему правовых теорий. В-третьих, рассмотрение концепции Р. Дворкина в свете базовых критериев типологии правовых теорий, по-видимому, дает иные результаты. Доктрина американского правоведа, с одной стороны, не является объединением всех (указанных И. Флоресом) перспектив, с другой - скорее подрывает классические критерии типологизации и, соответственно, ряд вытекающих из нее методологических возможностей. Таким образом, выводы мексиканского исследователя нуждаются в переосмыслении.

Итак, во-первых, можно говорить о разнопорядковости выделенных элементов подхода Р. Дворкина: конструктивности, интерпретативности, оценочности и интегративности. С одной стороны, они вполне независимы друг от друга, к тому же интерпретативность как позиция заявляется Р. Дворкиным лишь в 1980-е гг., тогда как иные черты просматриваются у него и ранее (например, в идеях конструктивизма / антиреализма права и морали как социальных институтов [12, ch. 6, 13], укорененности правовых принципов и институциональных обязанностей судей в политической морали сообщества [12, ch. 2-4], в идее права как «бесшовного сплетения» и фигуре вымышленного судьи Геркулеса [10, ch. 4], в сочетании концептуального и нормативного в юриспруденции [12, ch. 1]). С другой стороны, в доктрине интерпретативизма именно идея толкования (авторски понятая) становится теоретической и методологической рамкой, которая объединяет иные черты и перспективы и обусловливает оригинальность позиции мыслителя в правоведческих спорах.

Во-вторых, выделенные И. Флоресом черты скорее вычленяют ряд положений текстов Р. Дворкина, тогда как включение интерпретативизма в систему правоведения требует применения к нему базовых критериев типологии правовых теорий, причем дополненных значимым для современной юриспруденции делением теорий «внутренней» и «внешней» точек зрения. (Такое деление предполагает различение и методологизацию перспективы участника, принимающего и использующего правила некоего правопорядка, и наблюдателя, лишь рассуждающего о таких правилах и их практических аспектах с неких обособленных, обычно фактуальных, позиций $[15$, p. $240-$ 244]). В этом контексте интерпретативизм Р. Дворкина представляется частной, нормативной / оправдательной теорией «внутренней» точки зрения. Так, доктрина правоведа провозглашается как теория, рассуждающая с позиций участника юридической практики (прежде всего судьи), сосредоточенного на вопросах истинности и обоснованности правовых суждений $[8$, p. 2097; 11, p. 13-15]. Отсюда ее предметом выступает исторически и национально определенная юрисдикция: «интерпретативные теории по своей природе адресованы конкретной правовой культуре, обычно культуре их авторов» [11, p. 102]. Наконец, будучи частью нормативно-аргументативной юридической практики, ставя и решая задачи установления ее смысла и обоснования суждений о правах и обязанностях, интерпретативная доктрина имеет с необходимостью нормативные притязания [8, p. 2097-2104]. 


\section{ТЕОРИЯ И ПРАКТИКА ГОСУДАРСТВЕННО-ПРАВОВОГО РАЗВИТИЯ}

В-третьих, подобная оценка интерпретативизма Р. Дворкина, с одной стороны, говорит не об объединении им различных методологических перспектив в системе базовых теоретико-правовых координат (как утверждает И. Флорес), а скорее, о занятии им особой, более частной, методологической позиции. С другой стороны, данная позиция может считаться весьма радикальной - отвергающей ряд традиционных делений и проектов правовых теорий, а по сути подрывающей саму систему их типологизации. Так, Р. Дворкин оспаривает (значимый для позитивизма и др.) проект «внешней» правовой теории. По мнению правоведа, такой подход либо бесполезен (решает лишь периферийные для юриспруденции задачи, не связанные со смыслом юридической практики и истинностью правовых суждений), либо вообще несостоятелен (необоснованно презюмирует «точку Архимеда», находящуюся вне социальной практики, по сути скрывая свою включенность в морально-политические споры о праве) [8, p. 2097 ff.; 9, ch. 7]. Согласно Р. Дворкину, постижение права как аргументативной социальной практики невозможно без участия в ней, без вовлечения в ее «конструктивное истолкование», без применения здесь собственных представлений о силе и слабости используемых аргументов [11, p. 13-14]. А раз так, становится невозможной как чисто описательная юриспруденция (суждения которой, peконструирующие смыслы практики, должны сочетать описание и морально-политическую оценку), так и общая теория права (стремящаяся найти универсальные признаки крайне разнородных правовых систем с очень разными системами морали и политической идеологии [11, p. 102-103]).

В свете сказанного Р. Дворкин действительно оспаривает подход позитивизма (а равно других учений, принимающих классические методологические границы). Однако, вопреки И. Флоресу, это не означает «преодоления дихотомии позитивизма и естественного права». С одной стороны, при всех аргументах Р. Дворкина его оппоненты выдвинули целый ряд убедительных контрдоводов (альтернативную идею толкования, разграничение моральных и неморальных ценностей теории, плюрализм правовых доктрин и возможность общего объяснения и пр. $[6 ; 17$, ch. $6 ; 18])$, сохраняющих в полемическом поле правоведения позитивистскую позицию. С другой стороны, учение Р. Дворкина предлагает «преодоление» сложившейся локализации юснатурализма, ограниченной лишь вопросами должного, давая альтернативное позитивизму описание «права, как оно есть». Между тем, учитывая утверждение мыслителем необходимой связи права и морали, интерпретативизм, по сути, может считаться новой версией теории естественного права [1], переводящей ее классический спор с позитивизмом на методологический уровень.

\section{Выводы}

Рональд Дворкин предлагает самобытную правовую доктрину, следуя от оригинальной идеи толкования к формированию интерпретативной (герменевтической) концепции и методологии права и далее к общей проблематизации классических делений и типов правового теоретизирования. Провозглашаемая американским правоведом «Империя» действительно перекраивает привычную карту правовых теорий, проводя экспансионистскую политику и вынося весьма радикальные решения относительно статуса традиционных теоретических порядков и территорий. Успешность авторского проекта интерпретативизма - предмет дискуссий. Таковые, однако, не отменяют важный результат построений Р. Дворкина - обоснование серьезного методологического вызова традиционной структуре юриспруденции, обогатившего пространство современной философско-правовой мысли и создавшего новые стимулы для ее развития.

\section{ПРИМЕЧАНИЕ}

1 Публикация подготовлена при финансовой поддержке Российского фонда фундаментальных исследований, проект № 18-011-01213 «Право как целостность - право как интерпретация: теоретико-методологическая и проблемно-историческая реконструкция доктрины юридического интерпретативизма Рональда Дворкина (1967-1986)».

The reported paper was funded by RFBR, project no. 18-011-01213 "Law as integrity - law as interpretation: theoretical-methodological and problemic-historical reconstruction of Ronald Dworkin's doctrine of legal interpretivism (1967-1986)". 


\section{СПИСОК ЛИТЕРАТУРЫ}

1. Касаткин, С. Н. Концепция «раннего» Р. Дворкина как «третья теория права» / С. Н. Касаткин // Вестник Воронежского государственного университета. Серия: Право. - 2019. - № 2. - С. 94-107.

2. Кельзен, Г. Чистое учение о праве / Г. Кельзен. - 2-е изд. - СПб. : Алеф-Пресс, 2015. - 542 с.

3. Austin, J. Lectures on Jurisprudence, or The Philosophy of Positive Law / J. Austin. $-5^{\text {th }}$ rev. ed. 2 vols. - London : J. Murray, 1885. - 1132 p.

4. Bentham, J. An Introduction to the Principles of Morals and Legislation / J. Bentham. - London : Athlone Press, 1970. - 343 p.

5. Coleman, J. L. The Practice of Principle / J. L. Coleman. - New York: OUP, 2001.-252 p.

6. Dickson, J. Evaluation and Legal Theory / J. Dickson. - Oxford : Hart Publ., 2001. - 160 p.

7. Dworkin, R. A Matter of Principle / R. Dworkin. - Cambridge, Ma., London : HUP, 1985. $-425 \mathrm{p}$.

8. Dworkin, R. Hart's Posthumous Reply / R. Dworkin // Harvard Law Review. - 2017. Vol. 130. - P. 2096-2130.

9. Dworkin, R. Justice for Hedgehogs / R. Dworkin. - Cambridge, Ma. : HUP, 2011. - 506 p.

10. Dworkin, R. Justice in Robes / R. Dworkin. Cambridge, Ma., London : HUP, 2006. - 308 p.

11. Dworkin, R. Law's Empire/ R. Dworkin. Cambridge, Ma. : HUP, 1986. -483 p.

12. Dworkin, R. Taking Rights Seriously / R. Dworkin. $-2^{\text {nd }}$ ed. - Cambridge, Ma. : HUP, 1978. $-392 \mathrm{p}$.

13. Finnis, J. Natural Law and Natural Rights / J. Finnis. - Oxford : OUP, 1980. - 442 p.

14. Flores, I. B. The Legacy of Ronald Dworkin (1931-2013): A Legal Theory and Methodology for Hedgehogs, Hercules, and One Right Answers / I. B. Flores // Problema. - 2015. - № 9. - P. 157-192.

15. Hart, H. L. A. The Concept of Law / H. L. A. Hart. $-2^{\text {nd }}$ ed. with Hart's Postscript. Oxford : Clarendon Press, 1994. - 336 p.

16. Himma, K. E. Reconsidering a Dogma: Conceptual Analysis, the Naturalistic Turn, and Legal Philosophy / K. E. Himma // Law and Philosophy: Current Legal Issues. - Oxford : OUP, 2008. - P. 3-36.

17. Leiter, B. Naturalizing Jurisprudence

/ B. Leiter. - New York : OUP, 2007. - 300 p.

18. Raz, J. Ethics in the Public Domain / J. Raz.rev. edn. - Oxford : OUP, 1994. - 390 p.

19. Schauer, F. Positivism as Pariah / F. Schauer // The Autonomy of Law. Essays on Legal Positivism. Oxford: OUP, 1996. - P. 31-56.

20. Waldron, J. Normative (or Ethical) Positivism / J. Waldron // Hart's Postscript. - New York : OUP, 2001. -P. 410-434.

\section{REFERENCES}

1. Kasatkin S.N. Kontseptsiya «rannego» R. Dvorkina kak «tretya teoriya prava» [Conception of "Early" R. Dworkin as a "Third Theory of Law"]. Vesthik Voronezhskogo gosudarstvennogo universiteta. Seriya: Pravo [Bulletin of Voronezh State University. Series: Law], 2019, no. 2, pp. 94-107.

2. Kelsen G. Chistoe ucheniye o prave [Pure Doctrine of Law]. Saint-Petersburg, Alef-Press, 2015. $542 \mathrm{p}$.

3. Austin J. Lectures on Jurisprudence, or The Philosophy of Positive Law. $5^{\text {nd }}$ ed. 2 vols. London, J. Murray, 1885. 1132 p.

4. Bentham J. An Introduction to the Principles of Morals and Legislation. London, Athlone Press, $1970.343 \mathrm{p}$.

5. Coleman J.L. The Practice of Principle. New York, OUP, 2001. 252 p.

6. Dickson J. Evaluation and Legal Theory. Oxford, Hart Publ., 2001. 160 p.

7. Dworkin R. A Matter of Principle. Cambridge, Ma., London, HUP, 1985. 425 p.

8. Dworkin R. Hart's Posthumous Reply. Harvard Law Review, 2017, vol. 130, pp. 2096-2130.

9. Dworkin R. Justice for Hedgehogs. Cambridge, Ma., HUP, 2011. 506 p.

10. Dworkin R. Justice in Robes. Cambridge, Ma., London, HUP, 2006. 308 p.

11. Dworkin R. Law's Empire. Cambridge, Ma., HUP, 1986. 483 p.

12. Dworkin R. Taking Rights Seriously. $2^{\text {nd }}$ ed. Cambridge, Ma., HUP, 1978. 392 p.

13. Finnis J. Natural Law and Natural Rights. Oxford, OUP, 1980. 442 p.

14. Flores I.B. The Legacy of Ronald Dworkin (1931-2013): A Legal Theory and Methodology for Hedgehogs, Hercules, and One Right Answers. Problema, 2015, no. 9, pp. 157-192.

15. Hart H.L.A. The Concept of Law. $2^{\text {nd }}$ ed. with Hart's Postscript. Oxford, Clarendon Press, $1994.336 \mathrm{p}$.

16. Himma K.E. Reconsidering a Dogma: Conceptual Analysis, the Naturalistic Turn, and Legal Philosophy. Law and Philosophy: Current Legal Issues. Oxford, OUP, 2008, pp. 3-36.

17. Leiter B. Naturalizing Jurisprudence. New York, OUP, 2007. 300 p.

18. Raz J. Ethics in the Public Domain. rev. edn. Oxford, OUP, 1996. 390 p.

19. Schauer F. Positivism as Pariah. The Autonomy of Law. Essays on Legal Positivism. Oxford, OUP, 1996, pp. 31-56.

20. Waldron J. Normative (or Ethical) Positivism. Hart's Postscript. New York, OUP, 2001, pp. 410-434. 


\section{ТЕОРИЯ И ПРАКТИКА ГОСУДАРСТВЕННО-ПРАВОВОГО РАЗВИТИЯ}

\section{Information About the Author}

Sergey N. Kasatkin, Candidate of Sciences (Jurisprudence), Associate Professor, Department of Theory and History of State and Law, Samara Law Institute of the FSIN of Russia, Rylskaya St, 24v, 443022 Samara, Russian Federation; Associate Professor, Department of Theory of Law and Philosophy, Samara State University of Economics, Sovetskoy Armii St, 141, 443090 Samara, Russian Federation, kasatka_s@bk.ru,tigp@samlawin.ru,https://orcid.org/0000-0001-5541-9181

\section{Информация об авторе}

Сергей Николаевич Касаткин, кандидат юридических наук, доцент, доцент кафедры теории и истории государства и права, Самарский юридический институт ФСИН России, ул. Рыльская, 24в, 443022 г. Самара, Российская Федерация; доцент кафедры теории права и философии, Самарский государственный экономический университет, ул. Советской Армии, 141, 443090 г. Самара, Российская Федерация, kasatka_s@bk.ru, tigp@samlawin.ru, https://orcid.org/0000-0001-5541-9181 